\title{
Longevity of pearl millet (Pennisetum glaucum) seeds harvested at different stages of maturity
}

\author{
By N. KAMESWARA RAO** , S. APPA RAO, M. H. MENGESHA and \\ R. H. ELLIS*
}

Genetic Resources Unit. International Crops Research Institute for the Semi-Arid Tropics, Patancheru P. O.. Andhra Pradesh 502 324, India

Department of Agriculture, Liniersity of Reading. Earley Gate. P. O. Box 236. Reading RG6 $2 A T, U K$

(Accepted 15 April 199/)

\begin{abstract}
Summary
The storage potential of seeds harvested at weekly intervals after controlled pollination was studied in three diverse cytoplasmic male sterile pearl millet (Pennisetum glaucum) lines. In the first experiment in 1989, a comparison of $p_{50}$ (time for viability to decline to $50^{\circ}$ o during storage) among seeds of the line DSA 105A harvested 14,21, 28, 35 and 42 days after pollination (DAP), and then stored at $35^{\circ} \mathrm{C}$ with $15^{\circ}$, moisture content or 4()$^{\circ}{ }^{\circ} \mathrm{C}$ with $13^{\circ}{ }^{\circ}$ moisture content, showed that those harvested 35 DAP had the greatest longevity. In the second experiment in 1990, a comparison of $p_{50}$ within the lines $5141 \mathrm{~A}$ and $\mathrm{L} 67 \mathrm{~A}$ harvested 28,35 and 42 DAP, and then stored at $40{ }^{\circ} \mathrm{C}$ with $13^{\circ}{ }_{0}$ moisture content. showed that seeds of both lines harvested 42 DAP had the greatest longevity. In both the seasons, and in all three lines, maximum seed longevity $\left(p_{s 0}\right)$ was attained one week after physiological maturity (defined as the end of the grain filling period), which is therefore the optimum time of harvest to obtain good quality seeds for conservation.
\end{abstract}

Key words: Pearl millet, Pennisetum glaucum R.Br., seed maturity, seed storage longevity, genetic conservation

\section{Introduction}

Maintaining germplasm as seeds in genebanks is an economical and convenient method of conserving the genetic resources of crop plants (Anon., 1976). The most critical process of genebank management is regeneration (growing a sample of the seed accession to provide a fresh sample of seeds for further storage). Regeneration is expensive and there is also the risk of genetic drift due to selection pressure, recombination of genes, out-crossing, and handling errors (Anon., 1976). The potential storage life of seed accessions in genebanks, and hence the frequency of regeneration, is influenced by seed collection and harvesting practices (Smith, 1984).

Physiological maturity, defined as the attainment of maximum seed dry weight (Shaw \& Loomis, 1950), has been reported to be more or less coincident with the onset of full germination capacity in several crops (e.g. TeKrony, Pfeiffer \& Fellows, 1979; Ellis, Hong \& Roberts, 1987). According to Harrington (1972) physiological maturity marks the stage in seed development when the seeds begin to age, at which time they show maximum vigour. In

* To whom reprint requests should be sent.

Submitted as $\mathrm{KA}$. No. 1172 whe International Crops Research Institute for the Semi-Arid Tropics (ICRISAT) (C) 1991 Association of Applied Biologists 
four pearl millet (Pennisetum glaucum) lines mean maximum germination and seedling dry weights did coincide with physiological maturity (Appa Rao, Kameswara Rao \& Mengesha, 1992).

Does the maximum storage potential of seeds coincide with physiological maturity and decline thereafter? The evidence for this in Gramineae is somewhat equivocal. Rasyad, Van Sanford \& TeKrony (1990) reported that maximum storage potential in wheat (Triticum aestivum) occurred at or before physiological maturity but did not subsequently decline. McAlister (1943) found the longevity of immature seeds (pre-milk and milk stages) of several range and pasture species to be less than that of mature seeds (dough stage and harvest maturity), but Ellis \& Roberts (1981a) found no differences between the longevity of immature and mature (harvest maturity) barley (Hordeum vulgare) seeds, while Shands, Janisch \& Dickson (1967) reported a decline in barley seed longevity after harvest maturity.

The Genetic Resources Unit at ICRISAT maintains nearly 100000 seed accessions of five important crops of the semi-arid tropics (Mengesha, Khanna, Chandel \& Kameswara Rao, 1989). We conducted two experiments during the 1988 and 1989 post-rainy seasons and studied the quantitative differences in longevity of seeds harvested at different times after pollination in three cytoplasmic male sterile (CMS) pearl millet lines, in order to determine the optimum time to harvest seeds of good quality for conservation.

\section{Materials and Methods}

\section{Experiment I}

The CMS line DSA 105A (origin, Ghana) was grown in the field in an alfisol during December 1988 - March 1989 at the ICRISAT centre, Patancheru, in eight rows each $4 \mathrm{~m}$ long and $75 \mathrm{~cm}$ apart adjacent to six rows of the maintainer line. The seeds were sown on 25 December 1988. The distance between plants within rows was $10 \mathrm{~cm}$. To ensure that all seeds harvested from a spike were of the same age, emerging spikes were covered with parchment paper bags and when the maximum number of stigmas appeared receptive, they were handpollinated and covered again with these bags to prevent further pollination. In an attempt to minimise the effects of differences in environment during seed development, pollinations were adjusted so that seeds at all five maturity stages could be harvested at about the same time (Table 1). In addition, for most harvests, seeds from spikes pollinated on different dates were bulked (Table 1).

Between 14 and 51 spikes were collected for each maturity stage (Table 1) and dried for one week on perforated trays in a drying cabinet maintained at $15{ }^{\circ} \mathrm{C}$ and $15 \%$ relative humidity. This treatment reduced seed moisture contents to between $9.6 \%$ and $10.1 \%$. The samples were then hermetically stored at $4{ }^{\circ} \mathrm{C}$ for about 30 days until the determination of longevity. The differences in potential longevity of these five seed lots were studied by determining the germination of sub-samples of each after several different periods of storage in constant conditions; $40{ }^{\circ} \mathrm{C}$ with $13 \%$ moisture content, and $35^{\circ} \mathrm{C}$ with $15 \%$ moisture content. The determination of complete seed survival curves at a constant temperature and a constant moisture content, rather than one germination test after a single period of storage whether in a constant or changing seed storage environment, in order to estimate seed quality is in accordance with advice provided by Ellis \& Roberts (1980a, 1981b).

Seed moisture contents were determined gravimetrically using the high-constanttemperature oven method (Anon., 1985a,b) and are expressed on the wet-weight basis. They were raised to $13 \%$ or $15 \%$ by placing samples of known weight on moist paper towels and regularly reweighing until the required weight at each moisture content was reached. The seeds were then sealed in laminated aluminium foil packets and held at $4{ }^{\circ} \mathrm{C}$ for $48 \mathrm{~h}$ to ensure 
Table 1. Pollination and harcest date's for three CMS pearl millet line's harte'sted at differemt times after pollination

\begin{tabular}{|c|c|c|c|}
\hline $\begin{array}{l}\text { Days from } \\
\text { pollination } \\
\text { to harvest }\end{array}$ & Pollination date & Harvest date & $\begin{array}{l}\text { No. of } \\
\text { spikes } \\
\text { harvested }\end{array}$ \\
\hline \multicolumn{4}{|c|}{$D S A 10.5$} \\
\hline 14 & 23 February 1989 & 9 March 1989 & 32 \\
\hline 14 & 24 February 1989 & 10 March 1989 & 19 \\
\hline 21 & 16 February 1989 & 9 March 1989 & 12 \\
\hline 21 & 17 February 1989 & 10 March 1989 & 20 \\
\hline 28 & 11 February 1989 & II March 1989 & 20 \\
\hline 28 & 13 February 1989 & 13 March 1989 & 28 \\
\hline 35 & 15 February 1989 & 22 March 1989 & 29 \\
\hline 42 & 10 Februaly 1989 & 24 March 1989 & 14 \\
\hline \multicolumn{4}{|c|}{$5 / 4 / A$} \\
\hline 28 & 18 January 1990) & 15 February 1990 & 1.3 \\
\hline 28 & 20 January 1990 & 17 February 1990 & 5 \\
\hline 35 & 15 January 1990 & 19 February 1990 & 21 \\
\hline 42 & 10 January 1990 & 21 February 1990) & 5 \\
\hline 42 & 12 January 1990 & 23 February 1990 & 5 \\
\hline 42 & 16 January 1990 & 27 February 1990 & 7 \\
\hline \multicolumn{4}{|c|}{$\angle 67 A$} \\
\hline 28 & 19 January 1990) & 16 February 1990 & 1.1 \\
\hline 35 & 15 January 1990 & 19 February 1990 & 4 \\
\hline 35 & 17 January 1990 & 21 February 1990) & 2 \\
\hline 35 & 18 January 1990 & 22 February 1990) & 7 \\
\hline 42 & 10 January 1990 & 21 February 1990) & 9 \\
\hline 42 & 12 January 1990 & 2.3 February 1990 & 11 \\
\hline
\end{tabular}

even distribution of moisture within the seed lot. The moisture content of the seeds was then checked to ensure that all samples had the required moisture content. The seeds at each moisture content were then divided into sub-samples of $200-400$ seeds. Each sub-sample was sealed in a laminated aluminium foil packet. Nine samples of each maturity group at $13 \%$ moisture content were stored at $40 \pm 1{ }^{\circ} \mathrm{C}$ and nine at $15^{\circ}$, moisture content were stored at $35 \pm 1$ C. One sample was removed from each storage environment at weekly intervals and then tested for germination. An additional sample at each moisture content was also tested for germination before storage.

Each of the four or eight replicates of the germination test comprised 50 seeds tested on top of two moist filter papers (Whatman 181 ) in $9.0 \mathrm{~cm}$ Petri dishes and placed at random within an alternating temperature incubator maintained at $20 / 30^{\circ} \mathrm{C}(16 \mathrm{~h} / 8 \mathrm{~h})$. Final counts of normal germination were made after 10 days in test in accordance with the recommendations of the International Seed Testing Association (Anon., 1985h). The survival data for seeds of the various maturity stages in each storage environment were subjected to probit analysis (Roberts, 1972), in which a weighted transformed regression of percentage germination against time was performed.

\section{Experiment 2}

A further two CMS lines of diverse origin (5141A from India and L 67A derived from a cross between Indian and African lines) were sown on 17 November 1989 in an alfisol, the 
plants grown at the same density as Expt 1, and spikes harvested from each at three maturity stages in February 1990 (Table 1). These were treated identically to the seeds harvested in 1989 , except that samples were only stored in one environment $\left(40{ }^{\circ} \mathrm{C}\right.$ with $13 \%$ moisture content).

\section{Results and Discussion}

During storage all seed lots gradually lost viability, but differences among the seeds harvested at different stages of maturity were apparent (Fig. 1). In DSA 105A differences between the two storage environments were small whereas differences among harvest times were considerable (Fig. 1a,b). Most of these seed survival curves are typically sigmoid and can be described by negative cumulative normal distributions (Roberts, 1972). Within the viability equation developed to quantify loss in seed viability during storage in a wide range of storage environments (Ellis \& Roberts, 1980b), seed survival curves are described by

$$
v=K_{\mathrm{i}}-p / \sigma
$$

in which $v$ is probit percentage viability after storage in a constant environment for $p$ days, $K_{\text {I }}$ is a seed lot constant and $\sigma$ is the standard deviation of the frequency distribution of seed deaths in time (days). It has been shown in several diverse species that different seed lots stored under identical constant conditions have the same value of $\sigma$, and hence the same seed survival curve slope (Ellis \& Roberts, 1981b; Ellis, Osei-Bonsu \& Roberts, 1982; Kraak \& Vos, 1987). Comparison within each of Fig. $1 a, b, c$ and $d$ showed, not surprisingly, significant main effects of storage period $(P<0.005)$ and maturity stage at harvest $(P<0.005)$ but also significant interactions between these main effects $(P<0.025)$; i.e. the value of $\sigma$ varied among seed lots.

It is clear from each of Fig. $1 a$ and $b$, however, that the seed survival curves for all but the sample harvested 42 DAP are similar other than being displaced in time (i.e. the four lots harvested between 14 and 35 DAP provide results which conform to the hypothesis that $\sigma$ does not vary). In contrast, the two seed survival curves for the sample harvested 42 DAP are shallower. Comparison between curves for samples harvested 35 and 42 DAP show that the

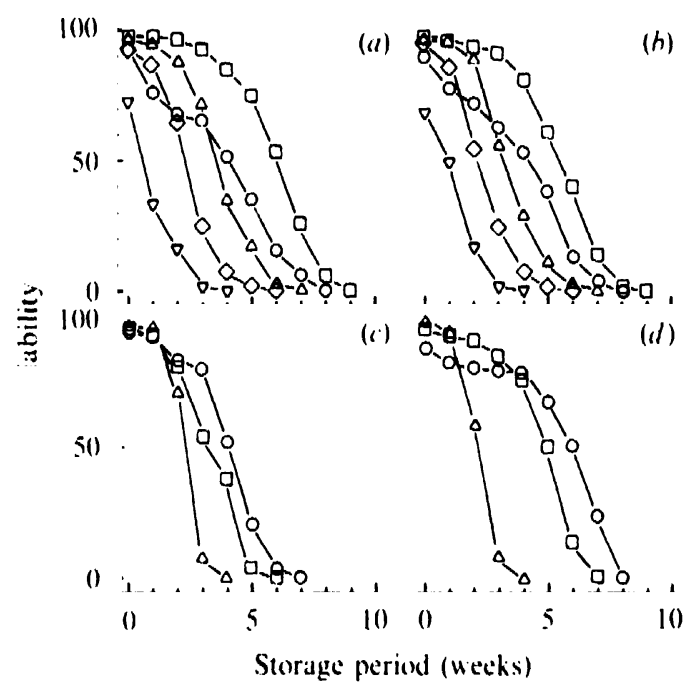

Fig. 1. Loss in viability of pearl millet seeds of CMS lines DSA 105A (a, h), 5141A (c), and L 67A (d) harvested $14(\nabla), 21(\diamond), 28(\triangle), 35(\square)$, and $42(0)$ days after pollination during subsequent hermetic storage at $35^{\circ} \mathrm{C}$ with $15^{\circ}$, moisture content $(a)$ or at $40^{\circ} \mathrm{C}$ with $13^{\circ}{ }_{\circ}$ moisture content $(b, c, d)$. 


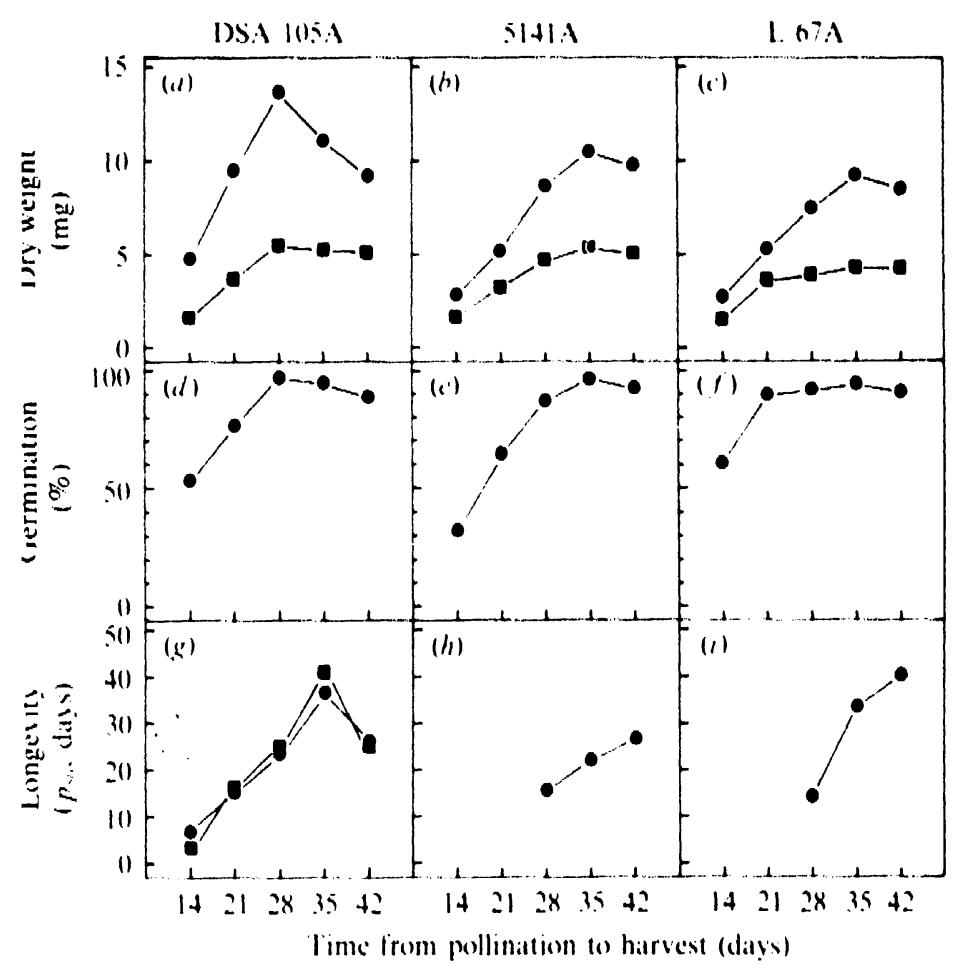

Fig. 2. Fffect of duration from pollination to harvest on mean seed dry weight (C, a c), mean seedling dry weight 14 days after sowing at $25 \mathrm{~S}^{\prime} \mathrm{C}(\mathrm{C}, \mathrm{a}(\mathrm{c})$. normal germination of fresh seeds $(0, d /)$, and seed longevity $\left(r_{41}\right.$. days) in hermetic storage at $35^{\circ} \mathrm{C}$ with $15^{\circ}$ " moisture content $(\boldsymbol{Q}, \mathrm{g})$ or 40 ) $\mathrm{C}$ with $13^{\circ}$. moisture content $\left(\bullet, g\right.$ i) for three ( MS pearl millet lines harvested in $1989(a, d, g)$ or 199()$\left(h, c, c^{\prime}, f, h, i\right)$. The values of $p_{s, 1}$ shown are the product of the estimates of $K_{1}^{\prime}$ and $\sigma$ (equation 1) derived by probit analysis of the observations shown in Fig. I. The data presented in $(h, c, c, f)$ are repeated from Appa Rao, Kameswara Rao \& Mengesha (1992).

shorter-lived seeds of the latter deteriorated rather more then the longer-lived seeds during this seven-day period on the mother plant (Fig. $1 a, b$ ), i.e. the viability of seeds harvested 42 DAP was less than that of seeds at 35 DAP, but the survival curve for seeds harvested 42 DAP was shallower. Even more dramatically, the same comparison within 5141 A and L 67A shows that the shorter-lived seeds of samples harvested 42 DAP were damaged during the last seven days on the mother plant, whereas the quality of the longer-lived seeds harvested 42 DAP was enhanced (Fig. lc,d), i.e. in both these lines the survival curves of seeds harvested 35 and 42 DAP cross with the latter showing higher viability for storage periods in excess of 14 (5141A) or 28 days (L 67A). We suggest two explanations for such behaviour (not mutually exclusive). First, the environment, particularly seed moisture content, during the final stages of maturation drying could vary within the spike, i.e. the moisture content of seeds at the core of the spike could take longer to equilibrate with the ambient environment than that of seeds at the periphery of the spike. Secondly, the sampling procedure used minimised variation in harvest date (Table 1), but one consequence was that early seed development did not necessarily occur under identical conditions.

The latter may help to explain the apparent decline in seed dry weights after physiological maturity. This was substantial in DSA 105A (Fig. 2a) but less marked in the other two lines (Fig. 2b,c). Although similar declines in seed dry weight after physiological maturity have sometimes been observed before in cereals (Housley, Kirleis, Ohm \& Patterson, 1982), they are difficult to explain other than by experimental error. 
The storage period until viability is reduced to $50 \%\left(p_{50}\right)$ is the most accurately determined longevity period (Roberts, 1972). This period of longevity was maximal 35 DAP in DSA 105A harvested in 1989 (Fig. $2 g$ ) and 42 DAP in 5141 A and L 67A harvested in 1990 (Fig. 2h,i), but in all three lines maximum longevity occurred one week after physiological maturity (Fig. 2). In contrast, both maximum germination of the fresh seeds and maximum mean seedling dry weight coincided with physiological maturity in all three lines, but neither declined greatly for seeds harvested 7 days later (Fig. 2a-f).

There is considerable reason then to question the assumption that all aspects of seed quality are maximal at physiological maturity. We suggest that in order to maximise subsequent seed storage longevity, pearl millet seeds should be harvested about one week after physiological maturity.

\section{Acknowledgements}

We thank Mr G. Dasaratha Rao and Mr C. Rajagopal Reddy, ICRISAT, for their assistance.

\section{References}

Anon. (1976). Report of IBPGR Working Group on Engineering Design and Cost Aspects of Long-term Seed Storage Facilities. Rome: International Board for Plant Genetic Resources, 19 pp.

Anon. (1985a). International rules for seed testing. Rules 1985. Seed Science and Technology 13, 299355.

Anon. (1985b). International rules for seed testing. Annexes 1985. Seed Science and Technology 13, 356513.

Appa Rao, S., Kameswara Rao, N. \& Mengesha, M. H. (1992). Germinability and vigor of pearl millet (Pennisetum glaucum) seeds harvested at different stages of maturity. Field Crops Research (submitted).

Ellis, R. H. \& Roberts, E. H. (1980a). Towards a rational basis for testing seed quality. In Seed Production, pp. 605-635. Ed. P. D. Hebblethwaite. London: Butterworths.

Ellis, R. H. \& Roberts, E. H. (1980b). Improved equations for the prediction of seed longevity. Annals of Botany 45, 13-30.

Ellis, R. H. \& Roberts, E. H. (1981a). An investigation into possible effects of ripeness and repeated threshing on barley seed longevity under six different storage environments. Annals of Botany 48, 9396.

Ellis, R. H. \& Roberts, E. H. (1981b). The quantification of ageing and survival in orthodox seeds. Seed Science and Technology 9, 373-409.

Ellis, R. H., Hong, T. D. \& Roberts, E. H. (1987). The development of desiccation-tolerance and maximum seed quality during seed maturation in six grain legumes. Annals of Botany 59, 23-29.

Ellis, R. H., Osei-Bonsu, K. \& Roberts, E. H. (1982). The influence of genotype, temperature and moisture on seed longevity in chickpea, cowpea and soya bean. Annals of Botany 50, 69-82.

Harrington, J. F. (1972). Secd storage and longevity. In Seed Biology, Volume III, pp. 145-245. Ed. T. T. Kozlowski. New York: Academic Press.

Housley, T. L., Kirleis, A. W., Ohm, H. W. \& Patterson, F. L. (1982). Dry matter accumulation in soft red winter wheat seeds. Crop Science 22, 290-294.

Kraak, H. L. \& Vos, J. (1987). Seed viability constants for lettuce. Annals of Botany 59, 353-359.

McAlister, D. F. (1943). The effect of maturity on the viability and longevity of the seeds of western range and pasture grasses. American Society Agronomy Journal 35, 442-453.

Mengesha, M. H., Khanna, P. P., Chandel, C. P. S. \& Kameswara Rao, N. (1989). Conservation of world germplasm collections of ICRISAT mandate crops. In Collaboration on Genetic Resources: Summary Proceedings of a Joint ICRISAT/NBPGR (ICAR) Workshop on Germplasm Exploration and Evaluation in India, pp. 65-70. Patancheru: ICRISAT. 
Rasyad, A., Van Sanford, D. A. \& TeKrony, D. M. (1990). Changes in seed viability and vigour during wheat seed maturation. Seed Science and Technology 18, 259-267.

Robertst E. H. (1972). Storage environment and control of viability. In Viability of Seeds, pp. 14-58. Ed. E. H. Roberts. London: Chapman and Hall.

Shands, H. L., Janisch, D. C. \& Dickson, A. D. (1967). Germination response of barley following different harvesting conditions and storage treatments. Crop Science 7, 444-446.

Shaw, R. H. \& Loomis, W. E. (1950). Bases for the prediction of corn yields. Plant Phy'siology 25. 225244.

Smith, R. D. (1984). The influence of collecting, harvesting and processing on the viability of seeds. In Seed Management Techniques for Genebanks, pp. 42. 82. Eds J. B. Dickie. S. Linington and J. T. Williams. Rome: International Board for Plant Genetic Resources.

TeKrony, D. M., Pfeiffer, T. \& Fellows, R. J. (1979). Physiological maturity in soybeans. Agronomy Journal 71, 771-775.

(Receiced 18 February 199l) 